\title{
Prevalence, clustering and combined effects of lifestyle behaviours and their association with health after retirement age in a prospective cohort study, the Nord- Trøndelag Health Study, Norway
}

Siri H. Storeng ${ }^{1 *}$, Erik R. Sund $d^{2,3,4}$ and Steinar Krokstad ${ }^{2,4}$

\begin{abstract}
Background: Lifestyle behaviours are potential risk factors for disease and mortality, but less is known about the association with health in retirement age. The aim of this paper was to study the prevalence, clustering and combined effects of lifestyle behaviours and their association with health outcomes in the first decade after retirement in a Norwegian cohort.

Methods: Participants were 55-64-year-olds at baseline in the Nord-Trøndelag Health Survey 2 (HUNT2, 1995-97) who also participated in HUNT3 (2006-08). Logistic regression analyses were used to investigate the association of daily smoking, physical inactivity, risky alcohol consumption, disturbed sleep duration, excessive sitting time and low social participation before retirement with self-rated health $(n=4022)$, life satisfaction $(n=5134)$, anxiety $(n=4461)$ and depression ( $n=5083$ ) after retirement, 11 years later.

Results: Low social participation and physical inactivity were the most prevalent lifestyle behaviours (41.1 and 40.6\%). Risky alcohol consumption and disturbed sleep were the lifestyle behaviours most strongly associated with poor selfrated health, poor life satisfaction and anxiety after retirement $\left(O R^{\prime} s=1.39-1.92\right)$. Physical inactivity was additionally associated with depression $(\mathrm{OR}=1.44(1.12-1.85))$. Physical inactivity had the largest population attributable fractions for reducing poor self-rated health and depression (14.9 and 8.8\%). An increasing number of lifestyle risk behaviours incrementally increased the risk for the adverse health outcomes.

Conclusions: Risky alcohol consumption and disturbed sleep duration were most strongly associated with poor health outcomes after retirement age. On a population level, increased physical activity before retirement had the largest potential for reducing adverse health outcomes after retirement age.
\end{abstract}

Keywords: Epidemiology, Lifestyle behaviours, Retirement age, Norway, HUNT

\footnotetext{
*Correspondence: siri.h.storeng@ntnu.no

'Department of Public Health and Nursing, Faculty of Medicine and Health Sciences, Norwegian University of Science and Technology, NTNU, Post box 8905, Håkon Jarls gate 11, N-7491 Trondheim, Norway

Full list of author information is available at the end of the article
}

(c) The Author(s). 2020 Open Access This article is licensed under a Creative Commons Attribution 4.0 International License, which permits use, sharing, adaptation, distribution and reproduction in any medium or format, as long as you give appropriate credit to the original author(s) and the source, provide a link to the Creative Commons licence, and indicate if changes were made. The images or other third party material in this article are included in the article's Creative Commons licence, unless indicated otherwise in a credit line to the material. If material is not included in the article's Creative Commons licence and your intended use is not permitted by statutory regulation or exceeds the permitted use, you will need to obtain permission directly from the copyright holder. To view a copy of this licence, visit http://creativecommons.org/licenses/by/4.0/ The Creative Commons Public Domain Dedication waiver (http://creativecommons.org/publicdomain/zero/1.0/) applies to the data made available in this article, unless otherwise stated in a credit line to the data. 


\section{Background}

In Norway, life expectancy is increasing along with a rising number of elderly [1]. A solution to combat an increasing dependency ratio (ratio of the dependent over the productive part of the working force) is to keep people longer in the workforce [2]. However, poor health increases risk of unemployment, disability pensioning and early retirement [3]. Oppositely, good health is a prerequisite for working into old age [4]. Retirement is a large transition period in people's lives, but the effect of retirement on health remains unsettled [5, 6]. High demands and low job control have been found to increase risk of disability pensions [6-9]. Health effects of retirement may also differ between socioeconomic groups [10].

Lifestyle behaviours are important risk factors for noncommunicable diseases, poor health and mortality [11]. Lifestyle behaviours have been found to cluster or coexist $[12,13]$ and tend to change around retirement $[14,15]$. A healthy lifestyle in midlife is associated with longevity [16] and the (pre-) retirement period may offer an opportunity to adopt healthier lifestyles [14]. Smoking, physical inactivity, high alcohol consumption and an unhealthy diet are often referred to as the "big four" potential modifiable risk factors influencing health and mortality [11]. In Norway, prevalence of daily smoking has decreased to $9 \%$ in 2019 [17]. Alcohol consumption in Norway has been increasing, especially in older age groups [18]. Further, increased sitting time, low social participation and disturbed sleep are emerging risk factors influencing health and mortality [19-31]. However, little is known about the importance of different lifestyle behaviours in working age on health in early years after retirement.

The aim of this study was to study the prevalence, clustering and combined effect of lifestyle behaviours and their association with self-rated health, life satisfaction, anxiety and depression in the first decade of retirement age, by using the Nord-Trøndelag Health Studies; HUNT2 (1995-97) and HUNT3 (2006-08) in a prospective cohort study.

\section{Methods}

\section{Population}

The selection of participants is shown in Fig. 1. The HUNT Study is a total county population-based study conducted with 11-year intervals (1984-86, 1995-97 and 2006-08) [32,33]. All inhabitants in the county of Nord-Trøndelag in Norway aged 20 and older were

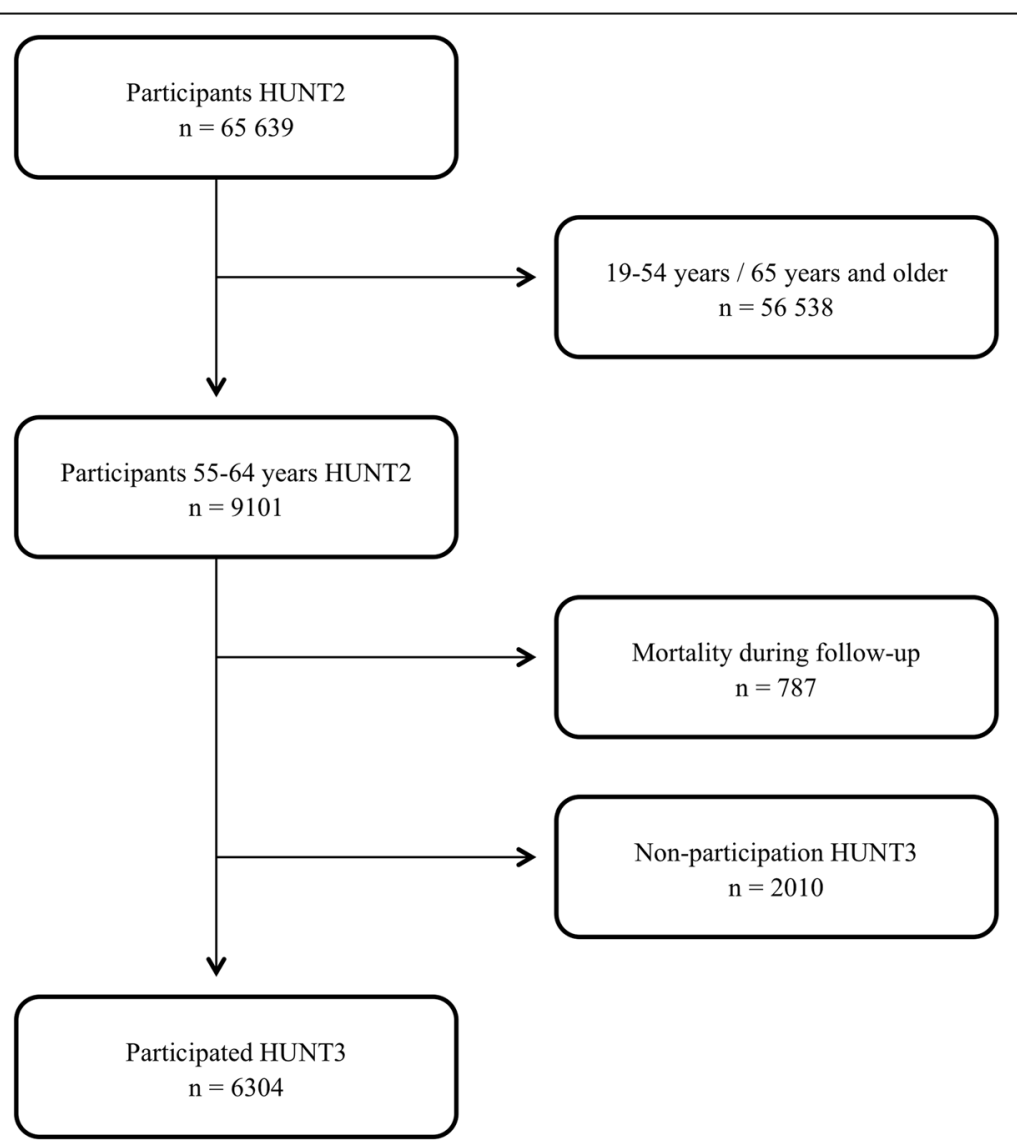

Fig. 1 Flow chart showing the selection of participants 
invited to participate. Participants undertook a clinical screening test, blood sample collection and completed questionnaires. The overall participation rate in HUNT2 and HUNT3 was 69.5 and 54.1\%, but higher among the middle aged (up to 85.5\%) [32, 33]. All participants signed a written consent form to participate in the HUNT Study and it was approved by the Regional Committee for Medical Research Ethics. The material in this study was 55-64-year-olds reporting good self-rated health $(n=4022) /$ good life satisfaction $(n=5134) /$ no anxiety $(n=4461) /$ no depression $(n=5083)$ at baseline in HUNT2 who also completed HUNT3 (65-77 years), with an average of 11 years follow-up time. 65 years was used as a cut-off as it corresponds to the average retirement age in Norway [34].

\section{Measures}

The lifestyle behaviours in HUNT2 were physical inactivity, daily smoking, risky alcohol consumption, prolonged sitting time, disturbance sleep duration and low social participation before retirement age (55-64 years). The lifestyle behaviours were selected based on previous research on their association with the studied health outcomes (summarised in Additional file 1). Questionnaires were developed by HUNT. Question texts, answer categories and coding of the independent variables are provided in Additional file 2. The cut-off for each lifestyle behaviour variable was based on available literature on their associations with health and mortality [19-21, 28, 35-40]. Unfortunately, we did not have enough information to include diet as a variable.

The outcome measures in HUNT3 were self-rated health, life satisfaction, anxiety and depression in the first decade after retirement age. The wording of selfrated health in the HUNT Study was "How is your health at the moment?" The original four answer categories "very good" "good" "poor" and "very poor" were dichotomised into "good" and "poor." The question about life satisfaction was; "Thinking about your life at the moment, would you say that you by and large are satisfied with life, or are you mostly dissatisfied?" It had seven answer categories ranging from "very satisfied" to "very dissatisfied". The first three and the last four answer categories were combined into "satisfied" and "dissatisfied." Anxiety and depression were measured using the Hospital Anxiety and Depression Score (HADS), consisting of a separate score for anxiety (HADS-A) and depression (HADS-D). The scale has been validated and shows high sensitivity and specificity for scores $\geq 8$ [41].

\section{Statistical analysis}

Prevalence estimates were calculated for the 12 most common lifestyle risk behaviours and combinations of these. Logistic regression models were used to assess lifestyle risk behaviours' association with self-rated health, life satisfaction, anxiety and depression in early years after retirement age. Population attributable fraction (PAF) was calculated for each lifestyle behaviour. PAF is the proportion of all cases that could be prevented by eliminating a specific risk factor. Lastly, logistic regression models were used to estimate the joint effect of increasing number of lifestyle risk behaviours on self-rated health, life satisfaction, anxiety and depression in early years after retirement. The models were adjusted for basic socio-demographic confounders (age, sex, education and marital status) and chronic illness. Nonparticipation in HUNT3 and mortality during follow-up from HUNT2 to HUNT3 could have introduced potential bias. This was evaluated in sensitivity analyses by including these competing outcomes in multinomial logistic regression models. Participants missing information on the relevant lifestyle variable in HUNT2 were excluded from that analysis. Odds ratios (OR) with $95 \%$ confidence intervals (95\% CI) were reported. Analyses were carried out in Stata SE version 14 [42].

\section{Results}

Table 1 shows descriptive statistics for 55-64-year-olds in HUNT2 who also participated in HUNT3 $(n=6304)$, with an average of 11 years follow-up time. The most prevalent lifestyle risk behaviours in HUNT2 were low social participation, physical inactivity and prolonged sitting time (41.1, 40.6 and 26.0\%, respectively). 787 participants in HUNT2 died before the start of HUNT3 (October 2006) and 2010 participated in HUNT2 but not in HUNT3. There was a high percentage missing on all the lifestyle behaviours (9.4-26.8\%), except for daily smoking (1.2\%). Few reported risky alcohol consumptions measured by CAGE $\geq 2(4.5 \%)$. Missing on the outcome variables varied from $1.6-15.5 \%$.

The most prevalent lifestyle risk behaviour combinations when none of the lifestyle variables were missing are shown in Table 2 . The most prevalent lifestyle risk behaviours were low social participation, physical inactivity and excessive sitting time. 50\% of the participants reported none or a combination of these lifestyle risk behaviours. Physical inactivity and low social participation remained the most prevalent lifestyle risk behaviours when including all 55-64-year-old participants in HUNT2 and missing on lifestyle behaviours equals "no" ( $n=9101$, Additional file 3). Risky alcohol consumption and disturbed sleep were not among the 12 most prevalent combinations in either of the two analyses.

The associations between lifestyle risk behaviours and self-rated health, life satisfaction, anxiety and depression after retirement age are shown in forest plots in Fig. 2. Corresponding odds ratios and 95\% confidence intervals from adjusted and unadjusted logistic regression analyses 
Table 1 Descriptive statistics for 55-64-year-olds in the Nord-Trøndelag Health Study, HUNT2 (1995-97, baseline) and HUNT3 (2006-08, outcome), $n=6304$

\begin{tabular}{|c|c|c|c|c|c|}
\hline \multirow{2}{*}{ Lifestyle variables (HUNT2) } & \multirow[b]{2}{*}{ n (\%) } & \multicolumn{2}{|c|}{ Adjustment variables (HUNT2) } & \multirow[t]{2}{*}{ Outcomes (HUNT3) } & \multirow[b]{2}{*}{ n (\%) } \\
\hline & & & n (\%) & & \\
\hline Daily smoking & & Sex & & Self-rated health & \\
\hline No & 4779 (75.8) & Women & $3362(53.3)$ & Good & 3899 (61.9) \\
\hline Yes & $1450(23.0)$ & Men & $2942(46.7)$ & Poor & $2159(34.3)$ \\
\hline Missing & $75(1.2)$ & Missing & $0(0)$ & Missing & $246(3.9)$ \\
\hline Physical activity & & Marital status & & Life satisfaction & \\
\hline Active & $3154(50.0)$ & Married & $5196(82.4)$ & Satisfied & $5649(89.6)$ \\
\hline Inactive & $2558(40.6)$ & Not married & $1102(17.5)$ & Dissatisfied & $554(8.8)$ \\
\hline Missing & $592(9.4)$ & Missing & $6(0.1)$ & Missing & $101(1.6)$ \\
\hline Sitting time & & Education & & Anxiety & \\
\hline$\leq 7 \mathrm{~h}$ & $3553(56.4)$ & Primary & $2269(36.0)$ & HADS-A $\leq 7$ & $4704(74.6)$ \\
\hline$\geq 8 \mathrm{~h}$ & $1638(26.0)$ & Secondary & $3171(50.3)$ & HADS-A $\geq 8$ & $623(9.9)$ \\
\hline \multirow[t]{2}{*}{ Missing } & $1113(17.7)$ & Tertiary & 858 (13.6) & Missing & $977(15.5)$ \\
\hline & & Missing & $6(0.1)$ & & \\
\hline Alcohol & & Chronic illness & & Depression & \\
\hline CAGE $\leq 1$ & $4333(68.7)$ & Yes & $2690(42.7)$ & HADS-D $\leq 7$ & $4813(76.4)$ \\
\hline CAGE $\geq 2$ & $283(4.5)$ & No & $3333(52.9)$ & HADS-D $\geq 8$ & $611(9.7)$ \\
\hline Missing & $1688(26.8)$ & Missing & $281(4.5)$ & Missing & $880(14.0)$ \\
\hline Social participation & & & & Mortality during follow-up & 787 \\
\hline Participates & $2978(47.2)$ & & & & \\
\hline Seldom, never & $2591(41.1)$ & & & Non-participation HUNT3 & 2797 \\
\hline Missing & $735(11.7)$ & & & & \\
\hline \multicolumn{6}{|l|}{ Sleep duration } \\
\hline $7-9 h$ & $4750(75.4)$ & & & & \\
\hline$\leq 6 / \geq 10 h$ & $767(12.2)$ & & & & \\
\hline Missing & 787 (12.5) & & & & \\
\hline
\end{tabular}

Abbreviations used in the table: CAGE Screening questionnaire for risky alcohol consumption, HADS Hospital Anxiety and Depression Scale, HADS-A HADS-Anxiety, HADS-D HADS-Depression, HUNT The Nord-Trøndelag Health Study

are provided in Additional files 4 and 5. Disturbed sleep duration, risky alcohol consumption, daily smoking, and physical inactivity were the lifestyle behaviours most strongly associated with poor self-rated health (OR's ranging from 1.31-1.49). Disturbed sleep duration and risky alcohol consumption were most strongly associated with poor life satisfaction $(\mathrm{OR}=1.47 \quad(0.82-2.62)$ and 1.47 (1.04-2.08)). Risky alcohol consumption was the lifestyle risk behaviour most strongly associated with anxiety $(\mathrm{OR}=1.92(1.02-3.62))$, followed by disturbed sleep duration $(\mathrm{OR}=1.39(0.95-2.04))$. Physical inactivity showed an inverse association with anxiety after retirement age $(\mathrm{OR}=0.88(0.66-1.16))$. Risky alcohol consumption and physical inactivity were most strongly associated with depression $(\mathrm{OR}=1.61 \quad(0.96-2.72)$ and $1.44(1.12-1.85))$. Low social participation and excessive sitting time had weak associations with the adverse health outcomes after retirement age in these analyses.

PAF for each lifestyle risk behaviour is shown in Fig. 3 and included in Additional file 4. Increased physical activity could theoretically have reduced the incidence of depression, self-rated health and poor life satisfaction in this population with $14.9,8.8$ and $4.7 \%$. Physical activity had a potential adverse effect on the incidence of anxiety (PAF -5.8\%). Increased social participation could potentially have reduced the incidence of depression and anxiety with 7.2 and $5.4 \%$. Smoking cessation could have reduced the incidence of poor self-rated health in this population with $6.2 \%$. PAF for reduced sitting time was small or negligible for all outcomes in this study population (PAF -1.1-0.34\%). An increasing number of combined lifestyle risk 
Table 2 The 12 most prevalent combinations of lifestyle risk behaviours in the Nord-Trøndelag Health Study (HUNT2, 1995-97), $n=5215$

\begin{tabular}{|c|c|c|c|c|c|c|c|c|}
\hline Combination & Prevalence (\%) & Cumulative \% & Smoking & Alcohol & Sitting & Inactive & Social & Sleep \\
\hline 1 & $635(12.2)$ & 12.2 & - & - & - & - & - & - \\
\hline 2 & $511(9.8)$ & 22.0 & - & - & - & - & + & - \\
\hline 3 & $438(8.4)$ & 30.4 & - & - & - & + & - & - \\
\hline 4 & $408(7.8)$ & 38.2 & - & - & + & - & - & - \\
\hline 5 & $403(7.8)$ & 46.0 & - & - & - & + & + & - \\
\hline 6 & $246(4.7)$ & 50.6 & - & - & + & - & + & - \\
\hline 7 & $238(4.6)$ & 55.2 & + & - & - & + & + & - \\
\hline 8 & $228(4.4)$ & 59.6 & + & - & - & - & + & - \\
\hline 9 & $209(4.0)$ & 63.6 & - & - & + & + & - & - \\
\hline 10 & 195 (3.7) & 67.3 & - & - & + & + & + & - \\
\hline 11 & 160 (3.1) & 70.4 & + & - & - & - & - & - \\
\hline 12 & $140(2.7)$ & 73.1 & + & - & - & + & - & - \\
\hline Total & 3811 (73.1) & & & & & & & \\
\hline
\end{tabular}

behaviours incrementally increased the risk for negative health outcomes after retirement age (Additional file 6). Having four or more risk factors increased the risk of poor self-rated health with $\mathrm{OR}=$ 2.39 (1.60-3.58).

Non-participation in HUNT3 and mortality during follow-up from HUNT2 to HUNT3 were potential competing outcomes to the health outcomes in HUNT3. This was evaluated in sensitivity analyses by using multinomial logistic regression models (Additional files 7-10). Daily smoking and low social participation before retirement were more strongly associated with non-participation in HUNT3 and mortality during follow-up, compared to the health outcomes in HUNT3. Risky alcohol consumption and disturbed sleep duration were more strongly associated with the adverse health outcomes after retirement age (except for depression), compared to nonparticipation in HUNT3 and mortality during follow-up.

\section{Discussion}

Low social participation, physical inactivity, excessive sitting time and combinations of these were the most prevalent lifestyle risk behaviours among 55-64-yearolds in HUNT2 in 1995-97. Risky alcohol consumption and disturbed sleep duration were less prevalent, but most strongly associated with poor self-rated health, poor life satisfaction and anxiety after retirement age. Physical inactivity was additionally associated with depression. Excessive sitting time and low social participation did not seem to be associated with the health outcomes measured after retirement age. At a population level, increased physical activity before retirement had the largest potential for reduction in the adverse health outcomes in early years after retirement. An increasing number of lifestyle risk behaviours incrementally increased the risk for the adverse health outcomes.

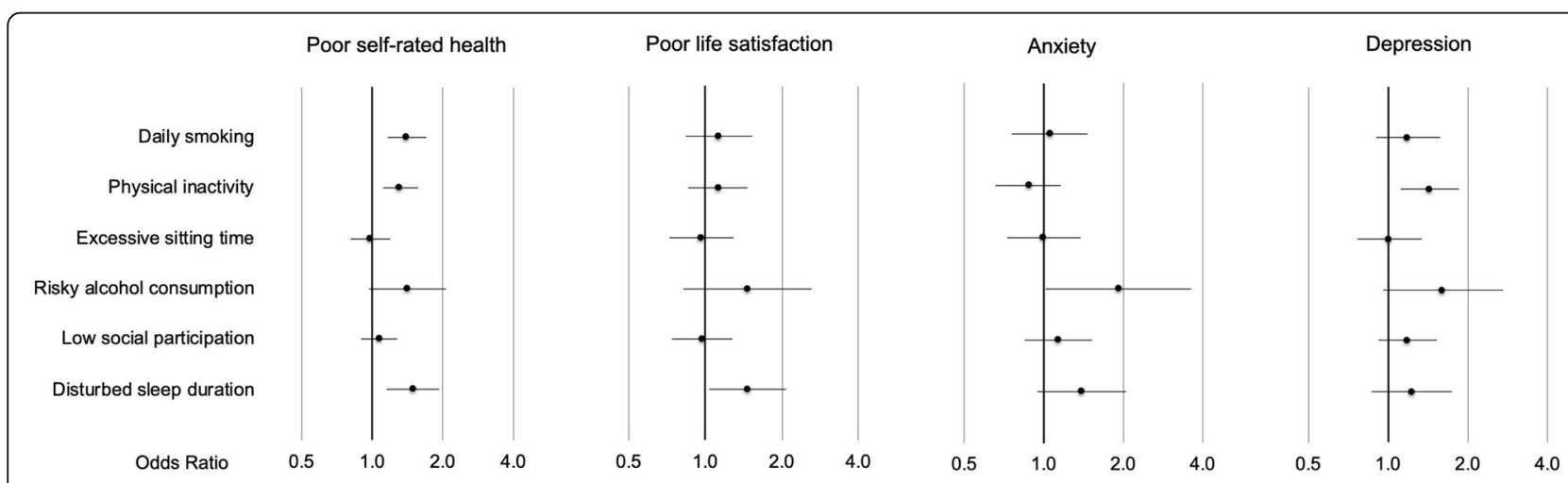

Fig. 2 Odds ratios for poor health, poor life satisfaction, anxiety and depression 


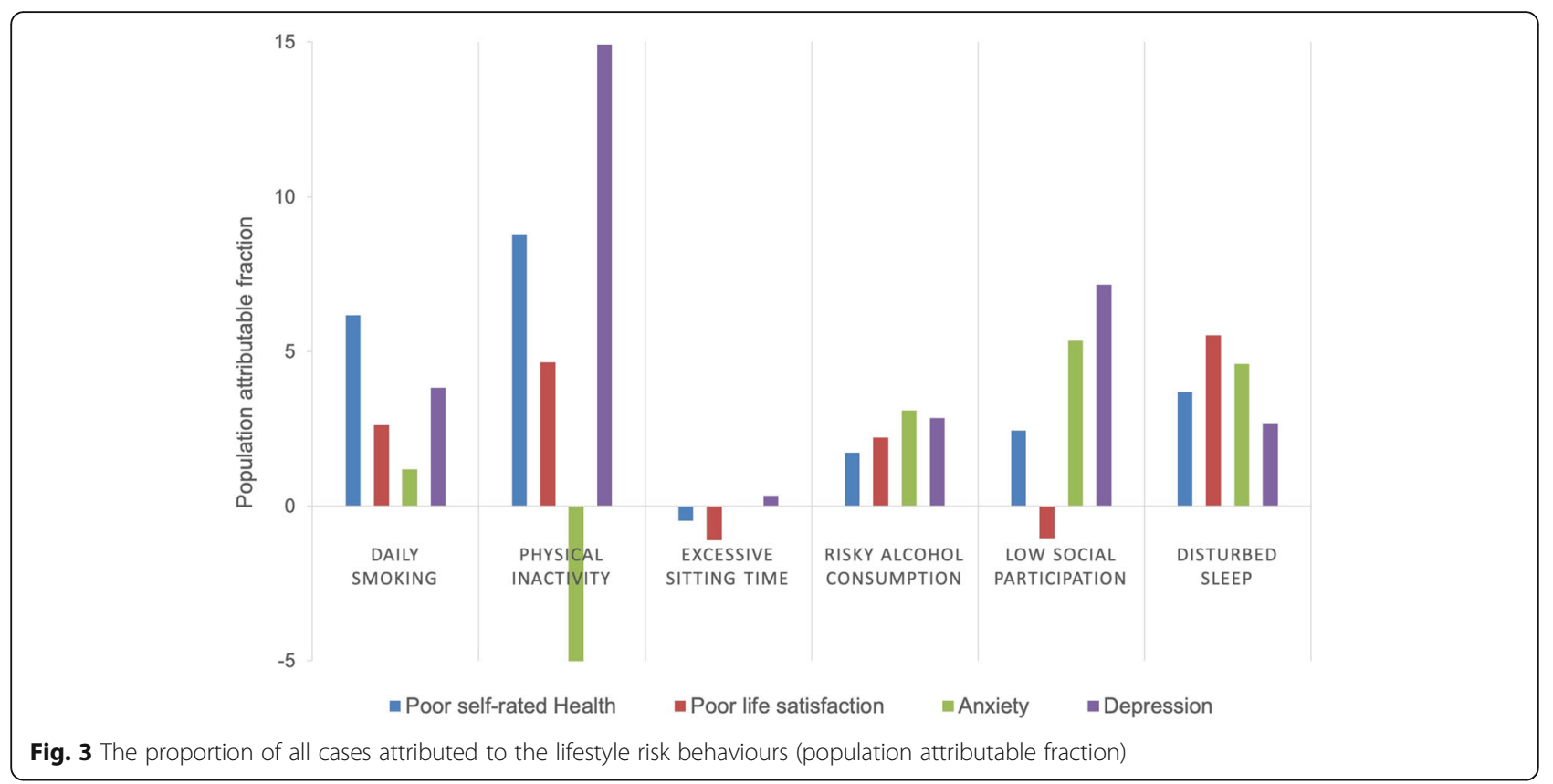

The main limitations of this study were the falling participation rate in the HUNT Study, healthy survivor bias and missing data on some of the lifestyle variables. Nonparticipants in HUNT3 have been found to have lower socioeconomic status, higher prevalence of several chronic diseases and higher mortality compared to participants [43]. Thus, the results from this study may be generalised to the healthier part of non-institutionalised older adults in populations comparable to the Norwegian setting.

Potential bias from loss of follow-up from HUNT2 to HUNT3 and mortality during the follow-up period was evaluated in sensitivity analyses where these competing outcomes were included in multinomial logistic regression models. Daily smoking and low social participation were more strongly associated with non-participation in HUNT3 and mortality during follow-up compared with the health outcomes. Risky alcohol consumption and disturbed sleep duration were more strongly associated with adverse health outcomes (except for depression) compared with non-participation in HUNT3 and mortality during follow-up. Thus, these lifestyle risk behaviours might be more important determinants for health compared with mortality in early years after retirement age. There was a high percentage missing on the questions regarding physical activity and risky alcohol consumption (measured by CAGE) in HUNT2, making the estimates less certain. Regretfully we did not have enough information on diet to include this as a lifestyle risk behaviour, which would have been relevant in this study of multiple lifestyle behaviours.

The most prevalent lifestyle risk behaviours among 55-64-year-olds in HUNT2 (1995-97) were low social participation (41.1\%), physical inactivity (40.6\%) and excessive sitting time (26.0\%). A systematic review from 2015 identified common patterns of co-occurring health behaviours [12]. These were 1) no lifestyle risk behaviours, 2) daily smoking combined with alcohol, and 3) having all "big four" risk behaviours; smoking, poor nutrition, excess alcohol and physical inactivity. Another systematic review from 2016 also found daily smoking and alcohol to be the most prevalent risk behaviour combination [13]. This was followed by physical inactivity and unhealthy diet, while socioeconomic status was the strongest predictor for engaging in multiple lifestyle risk behaviours [13].

In this study daily smoking was not among the most common lifestyle risk behaviour combinations. In Norway, prevalence of daily smoking was $29-31 \%$ in 1995-1997 [17]. Since smoking prevalence has been found to be higher among non-participants in the HUNT Study [43], in addition to $1.2 \%$ missing on the questionnaire (Table 1), smoking prevalence in HUNT2 might be underestimated. Prevalence of risky alcohol consumption doubled from HUNT2 (1995-97) to HUNT3 (2006-08) for men and women over 60 years [18]. 28.2\% participants aged 65 years and older reported drinking alcohol once or more weekly in HUNT3 [44]. In $201938 \%$ of $45-66$-year-old Norwegians reported drinking alcohol once or more weekly; higher among older adults and men compared with women [45]. Thus, this lifestyle risk behaviour is most likely more prevalent today. There were few and possibly extreme observations in the category CAGE $\geq 2$ in HUNT2, which may have underestimated the prevalence of risky alcohol 
consumption. Disturbed sleep duration, low social participation and excessive sitting time are seldom included in studies of multiple lifestyle risk behaviours [12, 13], making comparison difficult.

In this study, risky alcohol consumption, physical inactivity and disturbed sleep duration were the lifestyle risk behaviours most strongly associated with adverse health outcomes after retirement age. This is in line with previous findings showing associations between these risk behaviours and the studied health outcomes (summarised in Additional file 1) [26, 27, 29, 30, 46-58]. We found no or small associations between excessive sitting time and low social participation before retirement age with self-rated health, life satisfaction, anxiety and depression after retirement age. Previous studies have found associations between sedentary time $[23-25,36$, 59-61], low social participation [31, 62-65] and the studied health outcomes. However, drawbacks such as large heterogeneity in the studies, lack of substantial evidence and methodological weaknesses in available studies are highlighted $[66,67]$. Sedentary behaviour and low social participation are complex concepts that include several domains [31, 68], and the lack of standardised definitions and operationalisations hamper comparability between studies [12]. Lastly, causal pathways and directionality remain uncertain $[36,66,67,69]$.

Estimating PAF is important for guiding health policies. In this study, increasing physical activity before retirement showed the largest potential for reducing incidence of the adverse health outcomes after retirement age. This excludes anxiety where physical inactivity before retirement had an adverse effect (PAF -5.8\%). A study based on HUNT1 and HUNT2 found 12\% PAF for physical activity on the incidence of depression in the adult population, regardless of intensity [70]. The deviation from our PAF value (14.9\%) could be explained by differing time periods, age groups and cut-offs for physical activity. Worldwide, it is reported $6-10 \%$ incidence reduction of non-communicable diseases by engaging in physical activity [71], in addition to a substantial global economic advantage [72]. The study based on HUNT data also reported an inverse relationship between physical activity and anxiety [70], similar to our results. In systematic reviews there has been found positive associations between physical inactivity and anxiety $[23,56$, 57], but the directionality of the relationship remains unsettled [23, 57, 73]. Physical activity has been found to improve anxiety symptoms in intervention studies on healthy adults [56, 74], but aerobic exercise has not been found to be effective in treatment of clinical cases of anxiety [75]. Thus, the type of physical activity and severity of anxiety could play a role.

Risky alcohol consumption was strongly associated with the studied adverse health outcomes (OR 1.41-
1.92). However, the prevalence and potential reduction in incidence of the studied adverse health outcomes by eliminating this risk behaviour was low (PAF 1.7-3.1\%). Low social participation had the largest PAF for depression and anxiety (PAF 7.2 and 5.4\%), and thus the highest potential for improvement in mental health. Smoking cessation could potentially reduce the incidence of poor self-rated health, depression and anxiety with 6.2, 3.8 and $2.6 \%$. The prevalence of daily smokers in Norway decreased from 33\% 1995-1997 to 9\% in 2019 [17]. Thus, public health gains from reducing this lifestyle risk behaviour may already have been obtained. Reduced sitting time did not seem to have potential to affect the incidence of the adverse health outcomes included in this study (PAF -1.1-0.34\%). An increasing number of lifestyle risk behaviours incrementally increased the risk for adverse health outcomes. A few studies have found that engaging in multiple lifestyles risk behaviours is associated with poor self-rated health [76-78] lower health-related quality of life [79] more anxiety [80] and depression [80, 81]. And combined effects of lifestyle behaviours have been shown to affect all-cause mortality $[16,82]$.

\section{Conclusions}

The positive effects of adopting a healthy lifestyle around pensioning age presents opportunities for implementing interventions to enable people to work longer. Adopting or maintaining a healthy lifestyle should be a topic in pre-retirement programs, including health promotion interventions encouraging physical activity, smoking cessation, decreased alcohol intake and a favourable sleep duration. However, it is important to recognise that lifestyle is more than a result of individual choices and lifestyle changes often occur through interaction with others. As a consequence, it is paramount to also look at structural enabling and constraining conditions.

\section{Supplementary information}

Supplementary information accompanies this paper at https://doi.org/10. 1186/s12889-020-08993-y.

Additional file 1. Associations between lifestyle risk behaviours and selfrated health, life satisfaction, anxiety and depression.

Additional file 2. Question texts, answer categories and coding of independent variables in HUNT2 (1995-97).

Additional file 312 most prevalent combinations of lifestyle risk behaviours in HUNT2 (1995-97) disregarding missing. $n=9101$.

Additional file 4. Odds ratios $(\mathrm{OR})$ and population attributable fractions (PAF) from adjusted logistic regression analyses.* HUNT2 (1995-97, baseline) and HUNT3 (2006-08, outcome).

Additional file 5. Unadjusted logistic regression analyses. A longitudinal study from HUNT2 (1995-97, baseline) to HUNT3 (2006-08, outcome).

Additional file 6. Combined effects of lifestyle risk behaviours (HUNT2) on health outcomes (HUNT3), adjusted logistic regression analyses.* 
Additional file 7. Lifestyle risk behaviours (HUNT2, 1995-97) and odds ratios (OR) for competing outcomes (HUNT3), multinomial logistic regression analyses.*

Additional file 8. Lifestyle risk behaviours (HUNT2, 1995-97) and odds ratios (OR) for competing outcomes (HUNT3), multinomial logistic regression analyses.*

Additional file 9. Lifestyle risk behaviours (HUNT2, 1995-97) and odds ratios (OR) for competing outcomes (HUNT3), multinomial logistic regression analyses.*

Additional file 10. Lifestyle risk behaviours (HUNT2, 1995-97) and odds ratios (OR) for competing outcomes (HUNT3), multinomial logistic regression analyses.*

\section{Abbreviations}

CAGE: Questionnaire for risky alcohol consumption; Cut down, Annoyed, Guilty and Eye opener.; HADS: Hospital Anxiety and Depression Scale; HUNT: The Nord-Trøndelag Health Study; OR: Odds Ratio; PAF: Population Attributable Fraction

\section{Acknowledgements}

The Nord-Trøndelag Health Study (The HUNT Study) is a collaboration betweenHUNT Research Centre (Faculty of Medicine and Health Sciences, Norwegian University of Science and Technology, NTNU), Trøndelag County Council, Central Norway Regional Health Authority, and the Norwegian Instituteof Public Health.

\section{Authors' contributions}

All authors (SHS, ERS and SK) contributed substantially to the conceptualisation and design of the study. SHS performed the statistical analysis under supervision of ERS and SK, and all authors contributed to the interpretation of the data. SHS wrote the first draft of the article and ERS and SK revised it critically for important intellectual content. All authors have read and approved the final manuscript.

\section{Funding}

This work was supported by the Faculty of Medicine and Health Sciences at the Norwegian University of Science and Technology, NTNU.

\section{Availability of data and materials}

The Nord-Trøndelag Health Study (HUNT) has invited persons aged 13-100 years to three surveys between 1994 and 2008, and a fourth survey being completed in 2019 (HUNT4). Comprehensive data from more than 125,000 persons having participated at least once and biological material from78,000 persons are collected. The data are stored in HUNT databank and biological material in HUNT biobank. HUNT Research Centre has been given concession to store and handle these data by the Norwegian Data Inspectorate. The key identification in the data base is the personal identification number given to all Norwegians at birth or immigration, whilst de-identified data are sent to researchers. Due to confidentiality HUNT Research Centre wants to limit storage of data outside HUNT databank, and we have restrictions for researchers for handling of HUNT data files. We have precise information on all data exported to different projects and there are no restrictions regarding data export given approval of applications to HUNT Research Centre. http://www.ntnu.edu/hunt/data

\section{Ethics approval and consent to participate}

All participants in the HUNT study signed a written consent form to participate and the Regional Committee for Medical Research Ethics approved the study.

\section{Consent for publication}

Not applicable.

\section{Competing interests}

The authors declare that they have no competing interests.

\section{Author details}

'Department of Public Health and Nursing, Faculty of Medicine and Health Sciences, Norwegian University of Science and Technology, NTNU, Post box 8905, Håkon Jarls gate 11, N-7491 Trondheim, Norway. ${ }^{2}$ HUNT Research
Centre, Department of Public Health and Nursing, Faculty of Medicine and Health Sciences, Norwegian University of Science and Technology, NTNU, Levanger, Norway. ${ }^{3}$ Faculty of Nursing and Health Sciences, Nord University, Levanger, Norway. ${ }^{4}$ Levanger Hospital, Nord-Trøndelag Hospital Trust, Levanger, Norway.

Received: 13 September 2019 Accepted: 27 May 2020

Published online: 10 June 2020

\section{References}

1. Statistics Norway. Deaths. Statistics Norway; 2019 [updated 07.03.2019; cited 13.09.2019]. Available from: https://www.ssb.no/en/befolkning/statistikker/ dode/aar. Accessed 13 Sept 2019.

2. OECD. Pensions at a Glance 2017: OECD and G20 indicators. Paris: OECD Publishing; 2017.

3. van Rijn RM, Robroek SJ, Brouwer S, Burdorf A. Influence of poor health on exit from paid employment: a systematic review. Occup Environ Med. 2014; 71(4):295-301.

4. Solem PE, Finseraas H, Nicolaisen M. Dårlig fysisk helse - ingen hindring for å jobbe? [poor physical health - no hindrance for working?] article in Norwegian. Samfunnsspeilet. 2009;1:40-44.

5. Westerlund $H$, Kivimaki $M$, Singh-Manoux A, Melchior M, Ferrie JE, Pentti J, et al. Self-rated health before and after retirement in France (GAZEL): a cohort study. Lancet. 2009:374(9705):1889-96.

6. Staudinger UM, Finkelstein R, Calvo E, Sivaramakrishnan K. A global view on the effects of work on health in later life. Gerontologist. 2016;56(Suppl 2): S281-92.

7. Stansfeld S, Candy B. Psychosocial work environment and mental health--a meta-analytic review. Scand J Work Environ Health. 2006;32(6):443-62.

8. Theorell T, Hammarstrom A, Aronsson G, Traskman Bendz L, Grape T, Hogstedt C, et al. A systematic review including meta-analysis of work environment and depressive symptoms. BMC Public Health. 2015;15:738.

9. Knardahl S, Johannessen HA, Sterud T, Harma M, Rugulies R, Seitsamo J, et al. The contribution from psychological, social, and organizational work factors to risk of disability retirement: a systematic review with metaanalyses. BMC Public Health. 2017;17(1):176.

10. Schaap R, de Wind A, Coenen P, Proper K, Boot C. The effects of exit from work on health across different socioeconomic groups: a systematic literature review. Soc Sci Med. 2018;198:36-45.

11. Noncommunicable diseases. World Health Organization; 2018 [updated 01. 06.2018; cited 02.09.2019]. Available from: http://www.who.int/mediacentre/ factsheets/fs355/en/

12. Noble N, Paul C, Turon H, Oldmeadow C. Which modifiable health risk behaviours are related? A systematic review of the clustering of smoking, nutrition, alcohol and physical activity ('SNAP') health risk factors. Prev Med. 2015:81:16-41.

13. Meader N, King K, Moe-Byrne T, Wright K, Graham H, Petticrew M, et al. A systematic review on the clustering and co-occurrence of multiple risk behaviours. BMC Public Health. 2016;16:657.

14. Zantinge EM, van den Berg M, Smit HA, Picavet HS. Retirement and a healthy lifestyle: opportunity or pitfall? A narrative review of the literature. Eur J Pub Health. 2014:24(3):433-9.

15. Ding D, Grunseit AC, Chau JY, Vo K, Byles J, Bauman AE. Retirement-a transition to a healthier lifestyle?: evidence from a large Australian study. Am J Prev Med. 2016;51(2):170-8.

16. Loef $\mathrm{M}$, Walach $\mathrm{H}$. The combined effects of healthy lifestyle behaviors on all cause mortality: a systematic review and meta-analysis. Prev Med. 2012; 55(3):163-70.

17. Tobacco, alcohol and other drugs [Internet]. Statistics Norway; 2019 [updated 18.01.2019; cited 13.09.2019]. Available from: https://www.ssb.no/ en/statbank/table/05307/. Accessed 13 Sept 2019

18. Støver M, Bratberg G, Nordfjærn T, Krokstad S. Use of alcohol and prescription drugs among elderly (60+) in Norway. Norway: The HUNT Study; 2012

19. Cappuccio FP, D'Elia L, Strazzullo P. Miller MA. Sleep duration and all-cause mortality: a systematic review and meta-analysis of prospective studies. Sleep. 2010:33(5):585-92

20. Cappuccio FP, Cooper D, D'Elia L, Strazzullo P, Miller MA. Sleep duration predicts cardiovascular outcomes: a systematic review and meta-analysis of prospective studies. Eur Heart J. 2011;32(12):1484-92. 
21. Chau JY, Grunseit AC, Chey T, Stamatakis E, Brown WJ, Matthews CE, et al. Daily sitting time and all-cause mortality: a meta-analysis. PLoS One. 2013; 8(11):e80000.

22. Holt-Lunstad J, Smith TB, Layton JB. Social relationships and mortality risk: a meta-analytic review. PLoS Med. 2010;7(7):e1000316.

23. Teychenne M, Costigan SA, Parker K. The association between sedentary behaviour and risk of anxiety: a systematic review. BMC Public Health. 2015;15:513.

24. Teychenne M, Ball K, Salmon J. Sedentary behavior and depression among adults: a review. Int J Behav Med. 2010;17(4):246-54.

25. Zhai L, Zhang Y, Zhang D. Sedentary behaviour and the risk of depression: a meta-analysis. Br J Sports Med. 2015;49(11):705-9.

26. Zhai $L$, Zhang $H$, Zhang D. Sleep duration and depression among adults: a meta-analysis of prospective studies. Depress Anxiety. 2015;32(9):664-70.

27. Ishak WW, Bagot K, Thomas S, Magakian N, Bedwani D, Larson D, et al. Quality of life in patients suffering from insomnia. Innov Clin Neurosci. 2012; 9(10):13-26

28. Frange C, de Queiroz SS, da Silva Prado JM, Tufik S, de Mello MT. The impact of sleep duration on self-rated health. Sleep Sci. 2014;7(2):107-13.

29. Cox RC, Olatunji BO. A systematic review of sleep disturbance in anxiety and related disorders. J Anxiety Disord. 2016;37:104-29.

30. Bao YP, Han Y, Ma J, Wang RJ, Shi L, Wang TY, et al. Cooccurrence and bidirectional prediction of sleep disturbances and depression in older adults: meta-analysis and systematic review. Neurosci Biobehav Rev. 2017:75:257-73.

31. Schwarzbach M, Luppa M, Forstmeier S, Konig HH, Riedel-Heller SG. Social relations and depression in late life-a systematic review. Int J Geriatr Psychiatry. 2014;29(1):1-21.

32. Holmen J, Midthjell K, Krüger $\varnothing$, Langhammer A, Holmen TL, Bratberg G, et al. The Nord-Trøndelag health study 1995-97 (HUNT 2). Norsk Epidemiologi. 2003;13(1):19-32

33. Krokstad S, Langhammer A, Hveem K, Holmen TL, Midthjell K, Stene TR, et al. Cohort profile: the HUNT study, Norway. Int J Epidemiol. 2013;42(4):968-77.

34. Bjørnstad AF. Utviklingen i pensjonering og sysselsetting blant seniorer [Development of pensioning and employment among seniors] Article in Norwegian. Arbeid og velferd. 2018;2

35. Wisloff U, Nilsen TI, Droyvold WB, Morkved S, Slordahl SA, Vatten L. A single weekly bout of exercise may reduce cardiovascular mortality: how little pain for cardiac gain? 'The HUNT study, Norway. Eur J Cardiovasc Prev Rehabil. 2006;13(5):798-804.

36. Cuypers K, Krokstad S, Holmen TL, Skjei Knudtsen M, Bygren LO, Holmen J. Patterns of receptive and creative cultural activities and their association with perceived health, anxiety, depression and satisfaction with life among adults: the HUNT study, Norway. J Epidemiol Community Health. 2012;66(8):698-703.

37. Skogen JC, Overland S, Knudsen AK, Mykletun A. Concurrent validity of the CAGE questionnaire. Nord Trondelag Health Study Addict Behav. 2011;36(4): 302-7.

38. Aertgeerts B, Buntinx F, Kester A. The value of the CAGE in screening for alcohol abuse and alcohol dependence in general clinical populations: a diagnostic meta-analysis. J Clin Epidemiol. 2004;57(1):30-9.

39. Holtermann A, Mork PJ, Nilsen TI. Hours lying down per day and mortality from all-causes and cardiovascular disease: the HUNT study, Norway. Eur J Epidemiol. 2014;29(8):559-65.

40. Alvarez GG, Ayas NT. The impact of daily sleep duration on health: a review of the literature. Prog Cardiovasc Nurs. 2004;19(2):56-9.

41. Bjelland I, Dahl AA, Haug T, Neckelmann D. The validity of the hospital anxiety and depression scale. An updated literature review. J Psychosom Res. 2002;52(2):69-77.

42. StataCorp. Stata Statistical Software: Release 15. College Station: StataCorp LLC; 2017.

43. Langhammer A, Krokstad S, Romundstad P, Heggland J, Holmen J. The HUNT study: participation is associated with survival and depends on socioeconomic status, diseases and symptoms. BMC Med Res Methodol. 2012;12:143.

44. Tevik K, Selbaek G, Engedal K, Seim A, Krokstad S, Helvik AS. Use of alcohol and drugs with addiction potential among older women and men in a population-based study. The Nord-Trondelag Health Study 2006-2008 (HUNT3). PLoS One. 2017;12(9):e0184428.

45. Tobacco, alcohol and other drugs: Statistics Norway; 2019 [cited 20.03.2020]. Available from: https://www.ssb.no/en/statbank/table/12392/. Accessed 20 Mar 2020

46. Allan CA. Alcohol problems and anxiety disorders--a critical review. Alcohol Alcohol. 1995;30(2):145-51.
47. Boden JM, Fergusson DM. Alcohol and depression. Addiction. 2011;106(5): 906-14.

48. Sullivan LE, Fiellin DA, O'Connor PG. The prevalence and impact of alcohol problems in major depression: a systematic review. Am J Med. 2005;118(4): 330-41.

49. Valencia-Martin JL, Galan I, Rodriguez-Artalejo F. Alcohol and self-rated health in a Mediterranean country: the role of average volume, drinking pattern, and alcohol dependence. Alcohol Clin Exp Res. 2009;33(2):240-6.

50. Levola J, Aalto M, Holopainen A, Cieza A, Pitkanen T. Health-related quality of life in alcohol dependence: a systematic literature review with a specific focus on the role of depression and other psychopathology. Nord J Psychiatry. 2014;68(6):369-84

51. Alvaro PK, Roberts RM, Harris JK. A systematic review assessing Bidirectionality between sleep disturbances, anxiety, and depression. Sleep. 2013;36(7):1059-68.

52. Li L, Wu C, Gan Y, Qu X, Lu Z. Insomnia and the risk of depression: a metaanalysis of prospective cohort studies. BMC Psychiatry. 2016;16(1):375.

53. Baglioni C, Battagliese G, Feige B, Spiegelhalder K, Nissen C, Voderholzer U, et al. Insomnia as a predictor of depression: a meta-analytic evaluation of longitudinal epidemiological studies. J Affect Disord. 2011;135(1-3):10-9.

54. Vancampfort D, Stubbs B, Firth J, Hallgren M, Schuch F, Lahti J, et al. Physical activity correlates among 24,230 people with depression across 46 low- and middle-income countries. J Affect Disord. 2017:221:81-8.

55. Vancampfort D, Stubbs B, Koyanagi A. Physical activity correlates in people with anxiety: data from 46 low- and middle-income countries. Gen Hosp Psychiatry. 2017:49:26-31.

56. Mochcovitch MD, Deslandes AC, Freire RC, Garcia RF, Nardi AE. The effects of regular physical activity on anxiety symptoms in healthy older adults: a systematic review. Braz J Psychiatry. 2016;38(3):255-61.

57. Stubbs B, Koyanagi A, Hallgren M, Firth J, Richards J, Schuch F, et al. Physical activity and anxiety: a perspective from the world health survey. J Affect Disord. 2017:208:545-52.

58. Marques A, Peralta M, Martins J, Catunda R, Matos MG, Saboga NL. Associations between physical activity and self-rated wellbeing in European adults: a population-based, cross-sectional study. Prev Med. 2016;91:18-23.

59. Rosenkranz RR, Duncan MJ, Rosenkranz SK, Kolt GS. Active lifestyles related to excellent self-rated health and quality of life: cross sectional findings from 194,545 participants in the 45 and up study. BMC Public Health. 2013; 13:1071.

60. Boberska M, Szczuka Z, Kruk M, Knoll N, Keller J, Hohl DH, et al. Sedentary behaviours and health-related quality of life. A systematic review and metaanalysis. Health Psychol Rev. 2018;12(2):195-210.

61. Vancampfort D, Stubbs B, Herring MP, Hallgren M, Koyanagi A. Sedentary behavior and anxiety: association and influential factors among 42,469 community-dwelling adults in six low- and middle-income countries. Gen Hosp Psychiatry. 2018;50:26-32.

62. Bahramnezhad F, Chalik R, Bastani F, Taherpour M, Navab E. The social network among the elderly and its relationship with quality of life. Electron Physician. 2017:9(5):4306-11.

63. Choi Y, Lee KS, Shin J, Kwon JA, Park EC. Effects of a change in social activity on quality of life among middle-aged and elderly Koreans: analysis of the Korean longitudinal study of aging (2006-2012). Geriatr Gerontol Int. 2017:17(1):132-41.

64. Gariepy G, Honkaniemi H, Quesnel-Vallee A. Social support and protection from depression: systematic review of current findings in Western countries. Br J Psychiatry. 2016;209(4):284-93.

65. Santini ZI, Koyanagi A, Tyrovolas S, Mason C, Haro JM. The association between social relationships and depression: a systematic review. J Affect Disord. 2015;175:53-65.

66. Stamatakis E, Ekelund U, Ding D, Hamer M, Bauman AE, Lee IM. Is the time right for quantitative public health guidelines on sitting? A narrative review of sedentary behaviour research paradigms and findings. Br J Sports Med. 2019;53(6):377-82

67. van Uffelen JG, Wong J, Chau JY, van der Ploeg HP, Riphagen I, Gilson ND, et al. Occupational sitting and health risks: a systematic review. Am J Prev Med. 2010;39(4):379-88.

68. Rhodes RE, Mark RS, Temmel CP. Adult sedentary behavior: a systematic review. Am J Prev Med. 2012:42(3):e3-28.

69. Vermeulen-Smit E, Ten Have M, Van Laar M, De Graaf R. Clustering of health risk behaviours and the relationship with mental disorders. J Affect Disord. 2015;171:111-9. 
70. Harvey SB, Overland S, Hatch SL, Wessely S, Mykletun A, Hotopf M. Exercise and the prevention of depression: results of the HUNT cohort study. Am J Psychiatry. 2018;175(1):28-36.

71. Lee IM, Shiroma EJ, Lobelo F, Puska P, Blair SN, Katzmarzyk PT, et al. Effect of physical inactivity on major non-communicable diseases worldwide: an analysis of burden of disease and life expectancy. Lancet. 2012;380(9838): 219-29

72. Ding D, Lawson KD, Kolbe-Alexander TL, Finkelstein EA, Katzmarzyk PT, van Mechelen W, et al. The economic burden of physical inactivity: a global analysis of major non-communicable diseases. Lancet. 2016;388(10051): 1311-24.

73. Azevedo Da Silva M, Singh-Manoux A, Brunner EJ, Kaffashian S, Shipley MJ, Kivimaki M, et al. Bidirectional association between physical activity and symptoms of anxiety and depression: the Whitehall II study. Eur J Epidemiol. 2012;27(7):537-46

74. Conn VS. Anxiety outcomes after physical activity interventions: metaanalysis findings. Nurs Res. 2010;59(3):224-31.

75. Bartley CA, Hay M, Bloch MH. Meta-analysis: aerobic exercise for the treatment of anxiety disorders. Prog Neuro-Psychopharmacol Biol Psychiatry. 2013:45:34-9.

76. Lyu J, Lee SH, Kim HY. Associations between healthy lifestyles and health outcomes among older Koreans. Geriatr Gerontol Int. 2016;16(6):663-9.

77. Kwasniewska M, Kaleta D, Dziankowska-Zaborszczyk E, Drygas W, MakowiecDabrowska T. Lifestyle index and self-rated health status. Int J Occup Med Environ Health. 2007;20(4):349-56.

78. Tsai J, Ford ES, Li C, Zhao G, Pearson WS, Balluz LS. Multiple healthy behaviors and optimal self-rated health: findings from the 2007 behavioral risk factor surveillance system survey. Prev Med. 2010;51(3-4):268-74.

79. Duncan MJ, Kline CE, Vandelanotte C, Sargent C, Rogers NL, Di Milia L. Cross-sectional associations between multiple lifestyle behaviors and healthrelated quality of life in the 10,000 steps cohort. PLoS One. 2014;9(4):e94184.

80. Saneei P, Esmaillzadeh A, Keshteli AH, Reza Roohafza H, Afshar H, Feizi A, et al. Combined healthy lifestyle is inversely associated with psychological disorders among adults. PLoS One. 2016;11(1):e0146888.

81. Loprinzi PD, Mahoney S. Concurrent occurrence of multiple positive lifestyle behaviors and depression among adults in the United States. J Affect Disord. 2014;165:126-30

82. Krokstad S, Ding D, Grunseit AC, Sund ER, Holmen TL, Rangul V, et al. Multiple lifestyle behaviours and mortality, findings from a large populationbased Norwegian cohort study - the HUNT study. BMC Public Health. 2017;17(1):58.

\section{Publisher's Note}

Springer Nature remains neutral with regard to jurisdictional claims in published maps and institutional affiliations.

Ready to submit your research? Choose BMC and benefit from:

- fast, convenient online submission

- thorough peer review by experienced researchers in your field

- rapid publication on acceptance

- support for research data, including large and complex data types

- gold Open Access which fosters wider collaboration and increased citations

- maximum visibility for your research: over $100 \mathrm{M}$ website views per year

At $\mathrm{BMC}$, research is always in progress.

Learn more biomedcentral.com/submissions 